\title{
Secondary lesions in rabbits experimentally infected with Treponema pallidum
}

\author{
R A STRUGNELL, L DRUMMOND, AND S FAINE \\ From the Department of Microbiology, Monash University Medical School, Alfred Hospital, Prahan, Australia
}

SUMMARY Thirty rabbits infected with $10^{3}$ of either Nichols or Melbourne 1 strains of Treponema pallidum were observed for the development of secondary lesions, which appeared outside areas inoculated with viable treponemes. More rabbits infected with Melbourne 1 strain (eight of 15 rabbits) than were infected with the Nichols reference strain (three of 15 rabbits) developed secondary lesions. The mean (SD) incubation periods of secondary lesions were $52(8)$ days for rabbits infected with Melbourne 1 and 56 (4) days for rabbits infected with Nichols strain. These mean incubation periods did not correlate with appreciably increased concentrations of immune complexes or glycosaminoglycans in the serum of infected rabbits.

\section{Introduction}

Rabbits have been used as the model of choice for experimental syphilis largely because the primary lesion, which develops after intradermal inoculation with low numbers of Treponema pallidum, histologically and morphologically resembles the chancre of syphilis in man. ${ }^{1}$ The clinical similarity between natural syphilis in man and experimental syphilis in rabbits ususally ends, however, after the resolution of the primary lesion, as rabbits infected with the Nichols reference strain of $T$ pallidum subspecies pallidum ${ }^{2}$ do not commonly develop secondary syphilis lesions.

Though the pathogenesis of secondary syphilis has not yet been clarified, the generalised symptoms are thought to result from the growth of organisms that have disseminated from the primary site of infection. The reason for the widespread growth of $T$ pallidum despite demonstrable activation of immune mechanisms at the primary stage of the disease ${ }^{34}$ is not known; a number of investigations have suggested that the host immune response is suppressed at this time. ${ }^{5}-7$

Some studies have indicated that at least one of the symptoms of secondary syphilis, glomerulonephritis, is caused by the deposition of circulating immune complexes. ${ }^{8}-10$ Circulating immune complexes may also mediate the suppressive effect of syphilitic serum on lymphocyte transformation seen in in vitro assays

Address for reprints: Dr R A Strugnell, Department of Microbiology, Monash University Medical School, Alfred Hospital, Prahan, Victoria, Australia 3181.

Accepted for publication 13 August 1985 of cell mediated immunity in natural syphlis in man and experimental syphilis in rabbits, ${ }^{11} 12$ and the generalised nature of secondary syphilis may result from immunosuppression in vivo mediated by circulating immune complexes. Other reports have indicated that in vitro suppression of lymphocyte responsiveness is produced by an interaction of serum glycosaminoglycans with lymphocytes ${ }^{6}$ or mitogens, ${ }^{13}$ or both.

During a recent study of the ontology of immunity to chancre formation in experimental syphilis, rabbits were observed for the development of secondary lesions. ${ }^{14}$ In this paper we show a difference in the potential of $T$ pallidum strains to induce secondary lesions. We also investigated the relation between the formation of secondary lesions, serum concentrations of two postulated mediators of immunosuppression in syphilis (circulating immune complexes and glycosaminoglycans), and the development of immunity to chancre formation.

\section{Materials and methods}

\section{$T$ PALLIDUM ORGANISMS}

The Nichols ${ }^{15}$ and Melbourne $1^{16}$ strains of $T$ pallidum were maintained by passage in the testes of adult rabbits or stored frozen in minimum essential medium (Flow Laboratories, North Ryde, NSW, Australia) containing $10 \%$ (volume per volume) fetal calf serum and $15 \%$ (volume per volume) glycerol.

\section{RABBITS}

Adult male rabbits were bought from Monash University (Clayton, Victoria, Australia), housed 
individually at $16-18^{\circ} \mathrm{C}$, and fed antibiotic free food ad libitum.

\section{INFECTION AND CHALLENGE INOCULATIONS}

Thirty rabbits were injected intradermally on the dorsal midline $5 \mathrm{~cm}$ anterior to the tail with either $10^{3}$ Nichols (15 rabbits) or Melbourne 1 (15 rabbits) strain of T pallidum. At $2 \frac{1}{2}, 5,6 \frac{1}{2}, 7 \frac{1}{2}$, and 10 weeks after infection the dorsal surfaces of three rabbits from each group were clipped free of hair and injected with eight inocula of $10^{2}$ Nichols and eight inocula of $10^{2}$ Melbourne 1 strain of $T$ pallidum as described previously. ${ }^{14}$ All infected rabbits were observed for lesions, which developed outside the challenge inoculation areas before and after challenge.

\section{CIRCULATING IMMUNE COMPLEXES}

We measured concentrations of circulating immune complexes at different times after infection by the method of Maret et al. ${ }^{17}$ Serum samples were diluted to $5-8 \mathrm{mg}$ protein $/ 1$ with $0.1 \mathrm{~mol} / \mathrm{l}$ borate buffer $\mathrm{pH}$ 8.4 , mixed with an equal volume of $3.5 \%, 7 \%$, or $10 \%$ (weight per volume) polyethylene glycol 6000 (BDH Chemical, East Kew, Victoria, Australia) made up in $0.1 \mathrm{~mol} / \mathrm{l}$ borate buffer $\mathrm{pH} 8.4$, and incubated at $4^{\circ} \mathrm{C}$ for 18 hours. The precipitate was then collected by centrifugation at $5000 \times g$ for 30 minutes, and the supernatant was decanted. The precipitates were washed once with a solution of polyethylene glycol at the original concentration and dissolved in $0.1 \mathrm{~mol} / 1$ sodium hydroxide. The absorbance at $280 \mathrm{~nm}$ was measured in a Perkin-Elmer 125 double beam spectrophotometer.

\section{HEXURONIC ACID}

Hexuronic acid was precipitated from serum from normal and infected rabbits with cetylpyridinium chloride (Ajax Chemicals, Sydney, NSW, Australia). A volume of $1 \mathrm{ml}$ of serum was diluted to $5 \mathrm{ml}$ with distilled water, and $10 \%$ (weight per volume) aqueous cetylpyridinium chloride was added dropwise until precipitation was observed. After the tubes had been incubated at $37^{\circ} \mathrm{C}$ for 20 minutes, the precipitate was collected by centrifugation at $1500 \times g$ for 10 minutes, dissolved in $2 \mathrm{ml}$ of $2 \mathrm{~mol} / \mathrm{l}$ sodium chloride and precipitated again with $8 \mathrm{ml}$ absolute ethanol overnight at $4^{\circ} \mathrm{C}$. The precipitate was collected by centrifugation at $1000 \times g$ for 10 minutes and resuspended in $2 \mathrm{ml}$ distilled water. We measured the amount of hexuronic acid present in cetylpyridinium chloride precipitates by the method of Bitter and Muir. ${ }^{18}$ To assess the efficacy of this method in recovering hexuronic acid from serum, we added 10 $\mathrm{mg} / 1,20 \mathrm{mg} / \mathrm{l}, 50 \mathrm{mg} / \mathrm{l}$, or $100 \mathrm{mg} / \mathrm{l}$ hyaluronic acid (Helon; Pharmacia, North Ryde, NSW, Australia) to pooled normal rabbit serum that had previously been shown not to contain hexuronic acid.

\section{STATISTICS}

Student's $t$ test was performed as described previously. ${ }^{19}$

\section{Results}

SECONDARY LESIONS IN INFECTED RABBITS

We defined as secondary lesions all nodular dermal indurations that developed outside the grid area where challenge inoculations were made. Table I shows the incidence and incubation periods of secondary lesions that developed in rabbits infected with $T$ pallidum. Three of 15 rabbits infected with Nichols strain developed secondary lesions after challenge, in contrast with eight of 15 rabbits infected with the Melbourne 1 strain. The mean (SD) incubation periods of secondary lesions, which were constant and independent of the time before challenge, were 56 (4) days for the Nichols strain and 52 (8) days for the Melbourne 1 strain of $T$ pallidum. Two of three rabbits infected with Melbourne 1 strain six and a half weeks before challenge developed "satellite" secondary

TABLE I Incidence and incubation periods of secondary lesions in rabbits infected with $10^{3}$ Nichols or Melbourne 1 strains of Treponema pallidum and challenged with both strains.

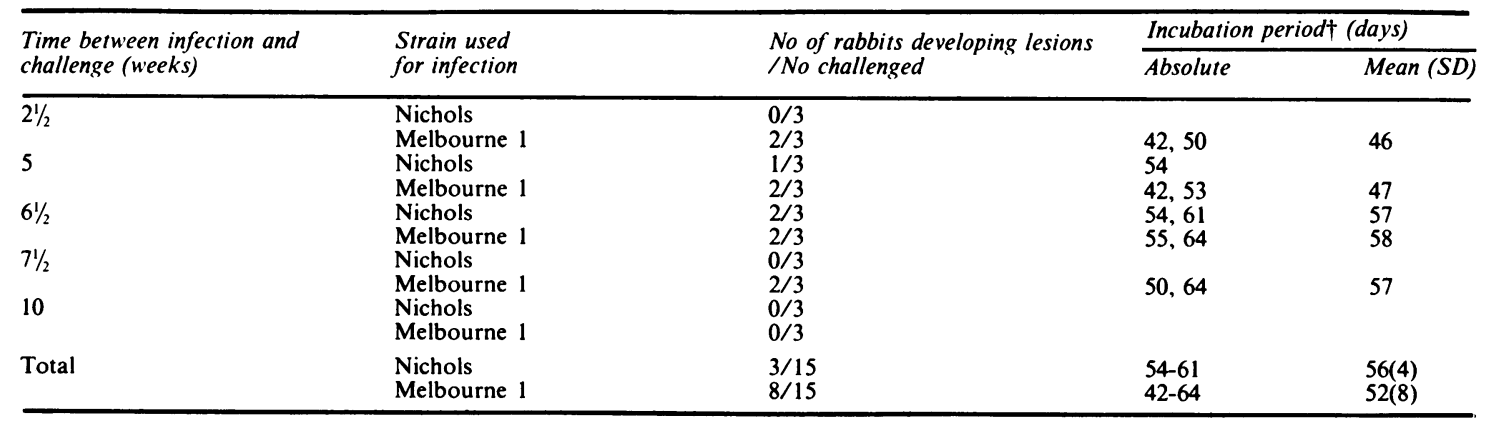

* All dermal lesions that appeared outside the marked grid where challenge inoculations were made were defined as secondary lesions.

+ Period between initial infection and first detected induration. 


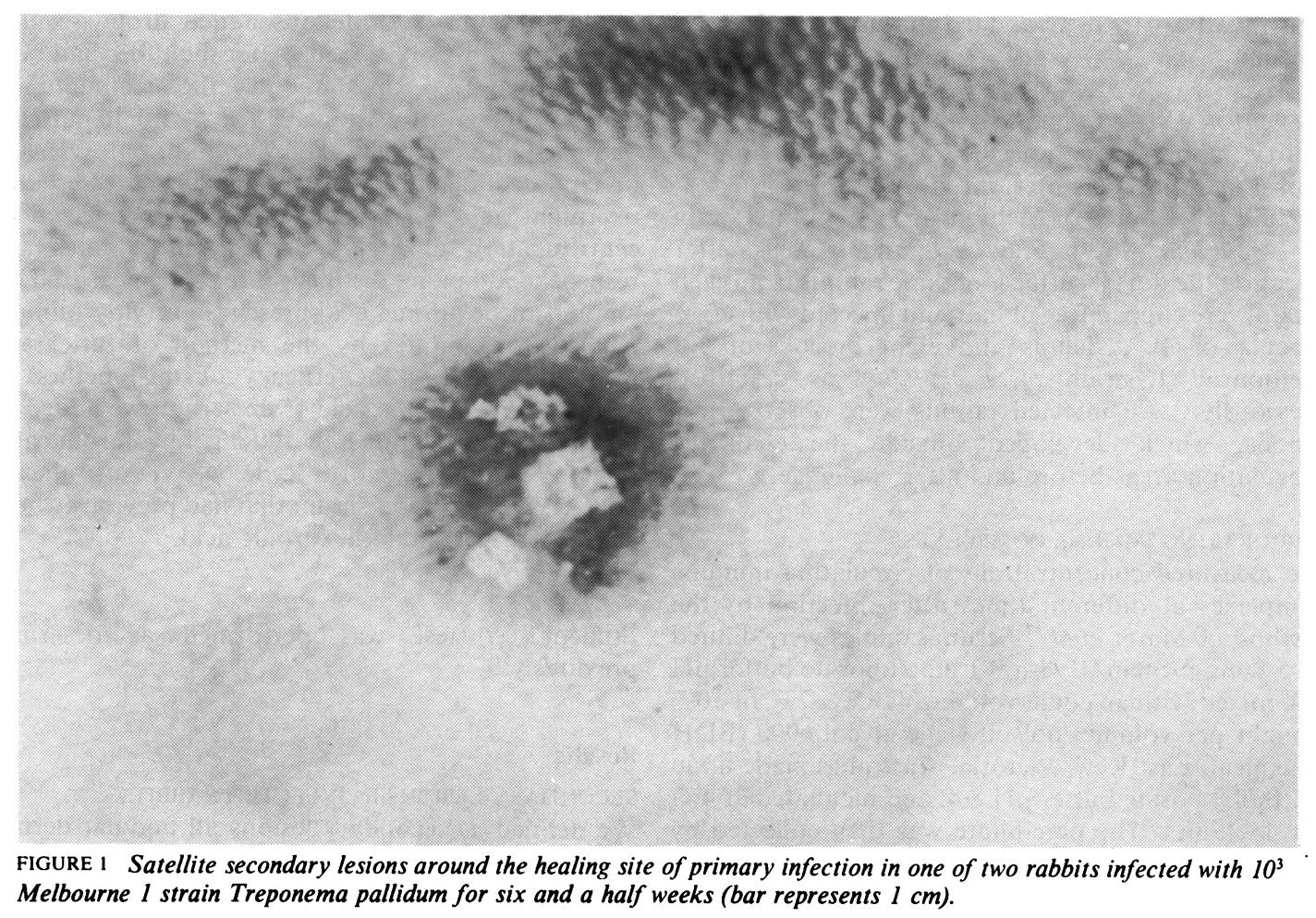

lesions at a radius of $2 \mathrm{~cm}$ around the initial site of infection (fig 1).

\section{CIRCULATING IMMUNE COMPLEXES IN INFECTED RABBITS}

We used $3 \%, 7 \cdot 5 \%$, and $10 \%$ polyethylene glycol to precipitate immune complexes from serum from normal (pre-infection) rabbits and those infected with $10^{3}$ Melbourne 1 or Nichols strains of $T$ pallidum for up to 10 weeks (fig 2). The $7.5 \%$ and $10 \%$ polyethylene glycol caused more precipitation from normal serum samples than $3 \%$ polyethylene glycol, thus increasing the "normal" baseline for material that was absorbed at $280 \mathrm{~nm}$. We saw no increase above the "normal" baseline in material precipitable by polyethylene glycol at concentrations of $3 \%$ and $7.5 \%$ (weight per volume) over the 10 week period. We did, however, see an apparent rise in the mean amount of material precipitated by $10 \%$ polyethylene glycol in serum from rabbits infected with Melbourne 1 strain six weeks after infection, but the large variability of individual rabbit responses meant that the result was not significant $(p>0.05)$.

\section{HEXURONIC ACID}

We detected no hexuronic acid in cetylpyridinium chloride precipitates of serum from normal or infected rabbits two to 10 weeks after infection with Nichols or 
Melbourne 1 strains of $T$ pallidum. We established the efficacy of cetylpyridinium chloride precipitation by adding to normal rabbit serum $5 \mathrm{mg} / 1$ to $50 \mathrm{mg} / \mathrm{l}$ hexuronic acid $(10 \mathrm{mg} / 1$ to $100 \mathrm{mg} / \mathrm{l}$ purified hyaluronic acid), $62 \%$ to $90 \%$ of which was recovered by cetylpyridinium chloride precipitation (table II).

TABLE II Recovery of added hexuronic acid from pooled normal rabbit serum by cetylpyridinium chloride precipitation (results represent mean of two samples)

\begin{tabular}{ll}
\hline Amount added $(\mathrm{mg} / \mathrm{l})$ & Amount $(\%)$ recovered $(\mathrm{mg} / \mathrm{l})$ \\
\hline 5 & $4(80)$ \\
10 & $9(90)$ \\
25 & $18(72)$ \\
50 & $31(62)$ \\
\hline
\end{tabular}

\section{Discussion}

Rabbits infected with $10^{3}$ Nichols or Melbourne 1 strains of $T$ pallidum develop primary syphilitic lesions after similar incubation periods (Strugnell, unpublished observation), and infection with either strain induces sustained immunity to chancre formation five to seven and a half weeks after inoculation (Strugnell et al unpublished observation).${ }^{14}$ This immunity to chancre formation is effective against both the strain used to infect the rabbits initially (the homologous strain) and the heterologous strain (Strugnell, unpublished results). ${ }^{14}$

Turner and Hollander reviewed other criteria that may be used to differentiate between strains of $T$ pallidum. ${ }^{20}$ These criteria included the degree of histological damage associated with dermal and testicular primary lesions, the degree to which lymph nodes are affected, the development of extended lesions, and the presence of local lesions in experimentally infected rabbits. More recently, $T$ pallidum strains have been shown to vary in their susceptibility to erythromycin. ${ }^{21}$ In the study reported here we found that rabbits infected with a relatively recent isolate of $T$ pallidum, Melbourne 1 strain, developed secondary lesions more often than rabbits infected with the Nichols reference strain. The incubation periods of secondary lesions that developed in rabbits infected with either Nichols or Melbourne 1 strain were constant. All lesions developed between six and nine weeks after infection, when sustained immunity to chancre formation is first established by superinfection with low numbers of $T$ pallidum.

The morphology of the secondary lesions varied between minor maculopapular indurations to lesions that progressed to ulceration similar to the primary chancre. Two rabbits that were challenged when secondary lesions most commonly developed (about six and a half weeks after initial infection) developed satellite secondary lesions around the healing primary chancre. This phenomenon may be evidence of so called "local immunity" in syphilis.

We were unsuccessful in attempts to show an association between the development of secondary lesions and serum concentrations of two postulated mediators of syphilitic immunosuppression, circulating immune complexes and glycosaminoglycans. Furthermore, hexuronic acid, a component of glycosaminoglycans, ${ }^{22}$ was not detected in the serum of infected rabbits at any time after infection. This finding was inconsistent with previous reports of "mucopolysaccharides" in the serum of rabbits infected with syphilis. ${ }^{613}$ The maximum concentrations of glycosaminoglycans found in the previous studies, $64 \mathrm{mg} / \mathrm{l}$, and $1 \mathrm{~g} / 1,{ }^{6}{ }^{13}$ were higher than the minimum sensitivity of the method used to recover hexuronic acid used in our study $(5 \mathrm{mg} / \mathrm{l})$. An explanation for the discrepancy may be that both previous studies used rabbits that were infected intratesticularly ${ }^{6}{ }^{13}$ or intravenously. ${ }^{13}$ Intravenous inoculation of rabbits with viable $T$ pallidum invariably leads to the development of syphilitic orchitis (Adams and Baughn, unpublished observation). We have shown previously that, after they have been infected with $T$ pallidum, rabbit testes increase the synthesis of macromolecules resembling glycosaminoglycans proportionately to the extent of disease. ${ }^{23}$ Thus the glycosaminoglycans detected in previous reports were possibly synthesised by and released from infected foci within the testes. The rabbits used in the present study were infected intradermally, and the degree of pathological change generated by a single dermal lesion may have been insufficient to release detectable concentrations of glycosaminoglycans into the serum.

Maret et al used precipitation with polyethylene glycol to assay immune complexes in syphilitic rabbits. ${ }^{17}$ In contrast to serum from rabbits infected with $T$ pallidum intravenously and intratesticularly, serum from intradermally infected animals did not precipitate with polyethylene glycol above levels obtained with normal rabbit serum. The authors stated, however, that in limited tests of serum from people with secondary syphilis, polyethylene glycol precipitation detected increased concentrations of circulating immune complexes. Baughn et al used the Raji cell and $\mathrm{Clq}$ binding assays and found a correlation between concentrations of circulating immune complexes and disseminated lesions. We observed an apparent rise in the mean level of material precipitable by polyethylene glycol during the period when secondary lesions first developed, six weeks after infection, but the large variability in responses by individual animals meant that the result was not significant.

Though this study did not elucidate the pathogenic 
mechanisms responsible for the development of symptoms associated with secondary syphilis, the observation that secondary lesions were of ten induced in rabbits infected with the Melbourne 1 but not the Nichols strain of $T$ pallidum emphasises two important points concerning the rabbit model of syphilis. Firstly, the Nichols strain of $T$ pallidum, which is commonly used in syphilis research, may not be typical of current environmental $T$ pallidum strains in its virulence for rabbits; passage through rabbits in the 70 years since its isolation ${ }^{24}$ may have lead to its attenuation. Secondly, under appropriate conditions of selection of strain and method of infection, the rabbit may be used in studies of a dermal syndrome that resembles secondary syphilis in man. Studies are continuing in this laboratory to assess the histopathology of secondary lesions in rabbits.

This study was supported by grants from Monash University and the National Health and Medical Research Council.

\section{References}

1. Sell S, Norris SJ. The biology, pathology and immunology of syphilis. Int Rev Exp Pathol 1983;24:203-69.

2. Smibert RM. Treponema. In: Krieg NR, Holt JG, eds. Bergey's manual of systematic bacteriology London: Williams and Wilkins, 1984. Vol 1:51.

3. Baker-Zander SA, Sell S. A histopathologic and immunologic study of the course of syphilis in the experimentally-infected rabbit. Am J Pathol 1980;101:387-403.

4. Sell S, Baker-Zander SA, Powell HC. Experimental syphilitic orchitis in rabbits: ultrastructural appearance of Treponema pallidum during phagocytosis and dissolution by macrophages in vivo. Lab Invest 1982;46:355-364.

5. Musher DM, Schell RF, Jones RH, Jones AM. Lymphocyte transformation in syphilis: an in vitro correlate of immune suppresion in vivo? Infect Immun 1975;11:1261-4.

6. Bey RF, Johnson RC, Fitzgerals TJ. Suppression of lymphocyte response to concanavalin A by mucopolysaccharide material from Treponema pallidum infected rabbits. Infect Immun 1979;26:64-9.

7. Fitzgerald TJ. Attachment of treponemes to cell surfaces. In: Schell RF, Musher DM, eds. Pathogenesis and immunology of treponemal infection. New York: Marcel Dekker, 1983: 195-227.
8. Braunstein GD, Lewis EJ, Galvenek EG, Hamilton A, Bell WR. The nephrotic syndrome associated with secondary syphilis: an immune deposit disease. Am J Med 1970;48:643-8.

9. Bhorade MS, Carag HB, Lee HJ, Potter EV, Dunea G. Nephropathy of secondary syphilis: a clinical and pathological spectrum. JAMA 1971;261:1159-66.

10. Gamble CN, Reardan JB. Immunopathogenesis of syphilitic glomerulonephritis. N Engl J Med 1975;292:499-54.

11. Baughn RE, Tsung KSK, Musher DM. Detection of circulating immune complexes in the sera of rabbits with experimental syphilis: possible role in immunoregulation. Infect Immun 1980;29:575-82.

12. Baughn RE. Immunoregulatory effects in experimental syphilis. In: Schell RF, Musher DM, eds. Pathogenisis and immunology of treponemal infection. New York: Marcel Dekker, 1983: 271-95.

13. Baughn RE, Musher DM. Reappraisal of lymphocyte responsiveness to concanavalin $A$ during experimental syphilis: evidence that glycosaminoglycans in the sera and tissues interfere with active binding sites on the lectin and not with the lymphocytes. Infect Immun 1982;35:552-9.

14. Strugnell RA, Faine S, Graves S. Response of syphilitic rabbits to reinfection with homologous and heterologous Treponema pallidum strains. Infect Immun 1984;45:561-5.

15. Graves SR, Sandok PL, Jenkin HM, Johnson RC. Retention of motility and virulence of Treponema pallidum (Nichols strain) in vitro. Infect Immun 1975;12:1116-20.

16. Graves $S$, Alden $J$. Limited protection of rabbits against infection with Treponema pallidum by immune rabbit sera. British Journal Venereal Diseases 1979;55:399-403.

17. Maret SM, Rauchbach AS, Folds JD. Immune complexes in experimental $T$ pallidum infection in rabbits. J Clin Lab Immunol 1982;8:47-50.

18. Bitter T, Muir HM. A modified uronic carbazole reaction. Anal Biochem 1962;4:330-4.

19. Ferguson GA. Statistical analysis in psychology and education. 3rd ed. New York: McGraw-Hill Book Co, 1971.

20. Turner TB, Hollander DH. Biology of the treponematoses. WHO Monograph Series 1957;35:1-277.

21. Stapleton JT, Stamm LV, Bassford PJ. The potential for the development of antibiotic resistance in the pathogenic treponemes. Rev Infect Dis 1985;7:5314-7.

22. Lindahl U, Hook M. Glycosaminoglycans and their binding to biological macromolecules. Annu Rev Biochem 1978;47:385-417.

23. Strugnell RA, Handley CJ, Drummond L, Faine S, Lowther DA. Graves SR. Polyanions in syphilis: evidence that glycoproteins and macromolecules resembling glycosaminoglycans are synthesised by host tissues in response to infection with Treponema pallidum. British Journal of Venereal Diseases 1984;60:75-82.

24. Nichols HA, Hough WH. Demonstration of Spirochaeta pallida in the cerebospinal fluid from a patient with nervous relapse following the use of salvarsan. JAMA 1913;60:108-10. 